\title{
Retrofitting of Reinforced Beam-Column Joints Using Hybrid Laminates
}

\author{
Rajeshwaran .M1, Manikandan . $\mathbf{T}^{2}$ \\ ${ }^{1}$ Post graduate student, PSNA College of Engineering and Technology, Dindigul-624622, Tamil Nadu, India \\ ${ }^{2}$ Assistant Professor, PSNA College of Engineering and Technology, Dindigul-624622, Tamil Nadu, India
}

\begin{abstract}
Thousands of reinforced concrete structures are constructed annually and a large number of these deteriorate or become unsafe before their design life. In buildings, the major part that fails is the beam-column joint connections. The behaviour of reinforced concrete moment resisting frame structures in recent earthquakes all over the world has highlighted the consequences of poor performance of beam column joints. In the last two decades, use of advanced composite materials such as Fiber Reinforced Polymers, (FRP), in strengthening reinforced concrete, (RC), structural elements have been increasing. Researches and design guidelines concluded that externally bonded FRP could increase the capacity of RC elements efficiently. This paper aims to study the performance of reinforced concrete beam-column joints strengthened by hybrid laminates. This paper presents an experimental program conducted to study the behaviour of RC beam-column joints strengthened with hybrid laminates. The program consists of a total of 4 specimens with overall dimensions of beam equal to $(100 \times 100 \times 900-\mathrm{mm})$ and column equal to $(100 \times 150 \times 1100-\mathrm{mm})$. The beam-column joints are to be tested under cyclic seismic loading up to failure to examine its behaviour. Different fiber directions, locations of combinations of carbon fiber reinforced polymer (CFRP) and glass fiber reinforced polymer (GFRP) laminates were attached to the beam-column joints to predict the best strengthening scheme. The test specimens were casted for estimating the load vs displacement, frequency vs amplitude, ductility, stiffness characteristics.
\end{abstract}

Keywords: Ductility, Flexure, Repair, Hybrid and Strengthening

\section{Introduction}

In the last few decades, moderate and severe earthquakes stroke different places in the world causing severe damage to reinforced concrete, (RC), structures. This requires upgrading of RC structures to resist more loads. In addition to the several advantages of FRP in strengthening, such as no corrosion characteristic, lightweight and high strength and consequently seismic loads are added to the strengthened structural elements. Unlike the better ductility achieved for columns wrapped by FRP due to confinement of concrete, beams strengthened with FRP have low ductility. In seismic zones, ductility of concrete element is a main design criterion. Several proposals were suggested to enhance this performance:

Strengthening of RC beam-column joints with HFRP laminates is introduced in this paper to increase both of their capacity and ductility. HFRP laminates, which consists of a combination of either carbon and glass fibers or glass and aramid fibers have a nonlinear stress-stain behavior (Belarbi et al. 1999). An experimental program was conducted to study the behaviour of RC beam-column joints strengthened with HFRP laminates. The program consists of a total of four T beam-column joints with overall height of $1050 \mathrm{~mm}$ and length of $1100 \mathrm{~mm}$. The beam-column joints were tested in three different configuration under cyclic loading to evaluate their ductility and energy dissipation. Same combinations of CFRP and GFRP laminates were attached to the beams to predict the best scheme of strengthening. Location of FRP as well as fiber direction were also varied. Different recommendations and design guidelines of RC beam-column joints strengthened by HFRP laminates are introduced.

\section{Hybrid Laminates}

In the last two decades, use of advanced composite materials such as Fiber Reinforced Polymers, (FRP), in strengthening reinforced concrete, (RC) structural elements have been increasing. In materials science, Composite laminates are assemblies of layers of fibrous composite materials which can be joined to provide required engineering properties, including in-plane stiffness, bending stiffness, strength, and coefficient of thermal expansion. The individual layers consist of high-modulus, high-strength fibers in a polymeric, metallic, or ceramic matrix material. The polymer matrix composites have been widely used for many applications. These are light in weight and easy for manufacturing. The hybrid fiber reinforced composites have been prepared to enhance the mechanical, thermal, damping properties compared to single-fiber reinforced composites. The fiber reinforced hybrid composites consist of two or more fiber in a matrix system. Researches and design guidelines concluded that externally bonded FRP could increase the capacity of RC elements efficiently. However, the linear stress-strain characteristics of FRP up to failure and lack of yield plateau have a negative impact on the overall ductility of the strengthened RC elements. Use of hybrid FRP laminates, which consists of a combination of either carbon and glass fibers or glass and aramid fibers change the behaviour of the material to a non-linear behaviour. In seismic zones, ductility of concrete element is a main design criterion. The nature and behaviour of hybrid laminates are different from monolithic aluminium as they are not isotropic in nature like that of metals. These hybrid laminates have a combination of isotropic properties of metal and anisotropic properties of the FRP material. . Fiber reinforced polymer, FRP, can be used in order to replace the missing steel or compensate the low concrete strength or structural faults in design. This technique does not result in an increase in the stiffness of the 


\section{International Journal of Science and Research (IJSR) \\ ISSN (Online): 2319-7064 \\ Index Copernicus Value (2013): 6.14 | Impact Factor (2015): 6.391}

structure and consequently no more seismic loads are added to the strengthened structural elements.

\section{Experimental Work}

The experimental program consists of testing total of four RC T-beam-column joints with overall dimensions of beam equal to $(100 \times 100 \times 900-\mathrm{mm})$ and column equal to $(100 \mathrm{x}$ $150 \times 1100-\mathrm{mm})$ as shown in fig. 3 . The beams were made fixed to the top of the actuator and the column is being held fixed at the bottom.

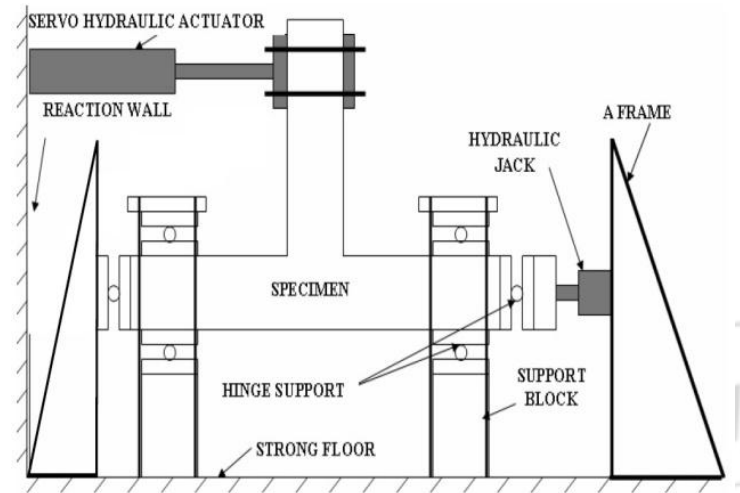

Figure 1

An MTS actuator of $100 \mathrm{kN}$ capacity with frame was used for testing of specimens. The column was placed in horizontal position while the beam was placed in vertical position in the set-up. An axial load of $10 \%$ of gross capacity of column was applied to the column to represent gravity load. The load on column was applied by a $5 \mathrm{kN}$ using jack, which was properly calibrated. To simulate support condition at both ends of the column, fixed supports were used.With the help of hydraulic dynamic actuator, cyclic displacement was applied to all the specimens. The displacement controlled load with a frequency of $0.025 \mathrm{~Hz}$ was applied to all the test specimens. The Experimental Study on BeamColumn Joint with Fibres under Cyclic Loading with displacement histories applied to all specimens are shown in Figure 1 and 3 . The reinforcement details are shown in Figure 2.Different cycles of specific amplitude consisting of a push and a pull segment were repeated before the next increment in displacement was made. The first amplitude applied to all the specimens was $\pm 2 \mathrm{~mm}$. The next amplitude applied was followed by $\pm 4 \mathrm{~mm}$ to $\pm 26 \mathrm{~mm}$. The experiment was stopped for specimen $\pm 26 \mathrm{~mm}$ for control. The displacement amplitude increment was $16 \mathrm{~mm}$.

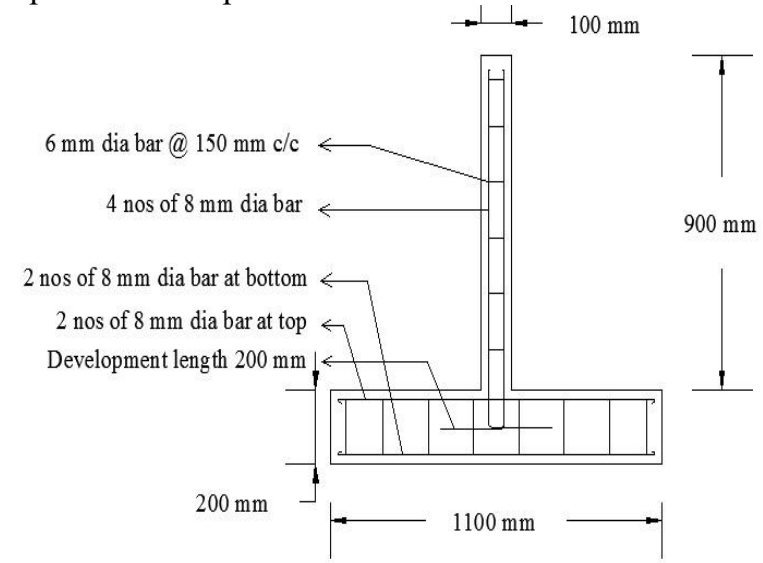

RFINFORCFMFNT DFTAII ING OF RFAM-COIIIMN IOINT
Figure 2

\section{Testing of Specimen}

The test set up of this specimen is shown in Figure 1. Many observations have been taken during experiment and by analysis hysteresis loop. In Figure 4 a close view of the joint damaged area is shown. The first crack appeared in the junction of Beam-Column joint at a displacement amplitude of $\pm 16 \mathrm{~mm}$.

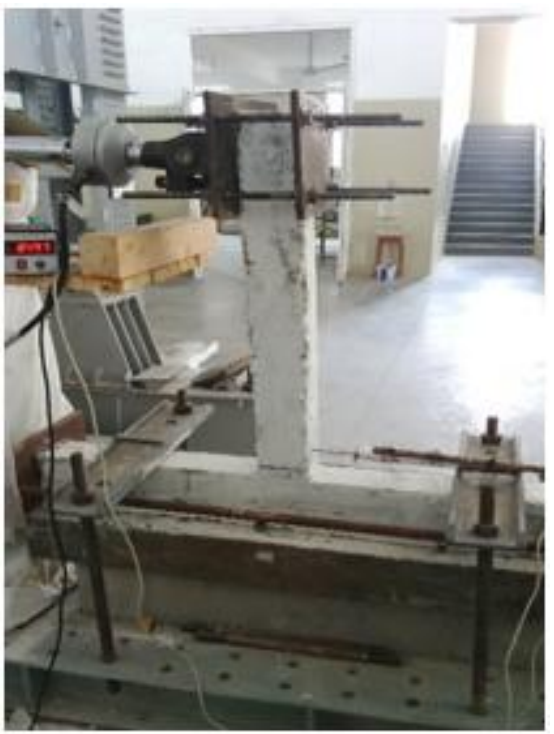

Figure 3

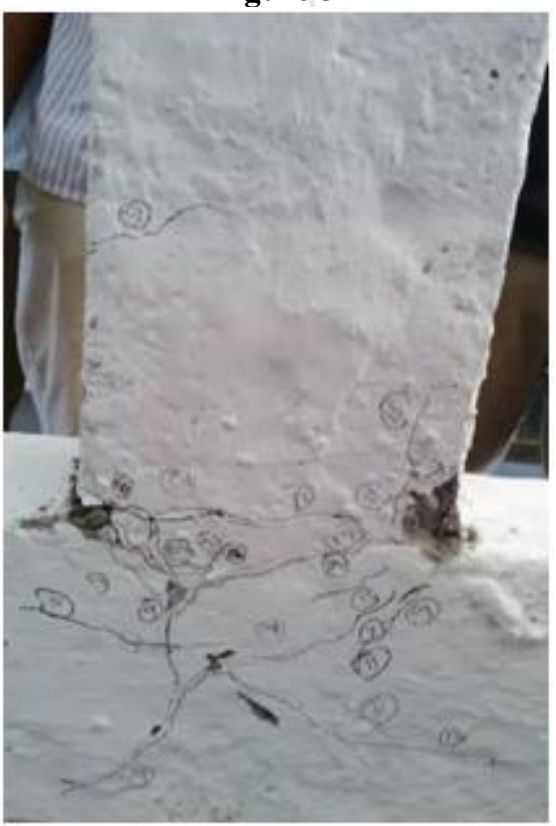

Figure 4

Further, many numbers of cracks were increased in the junction when displacement amplitude was increased gradually. From hysteresis loop analysis, it can be observed that the maximum load capacity of RCBC specimen is $12 \mathrm{kN}$ in push direction at $13^{\text {th }}$ cycle at a displacement of $\pm 26 \mathrm{~mm}$, similarly the maximum load of $16 \mathrm{kN}$ in the pull direction is observed at $11^{\text {th }}$ cycle at a displacement of $22 \mathrm{~mm}$. 
International Journal of Science and Research (IJSR)

ISSN (Online): 2319-7064

Index Copernicus Value (2013): 6.14 | Impact Factor (2015): 6.391

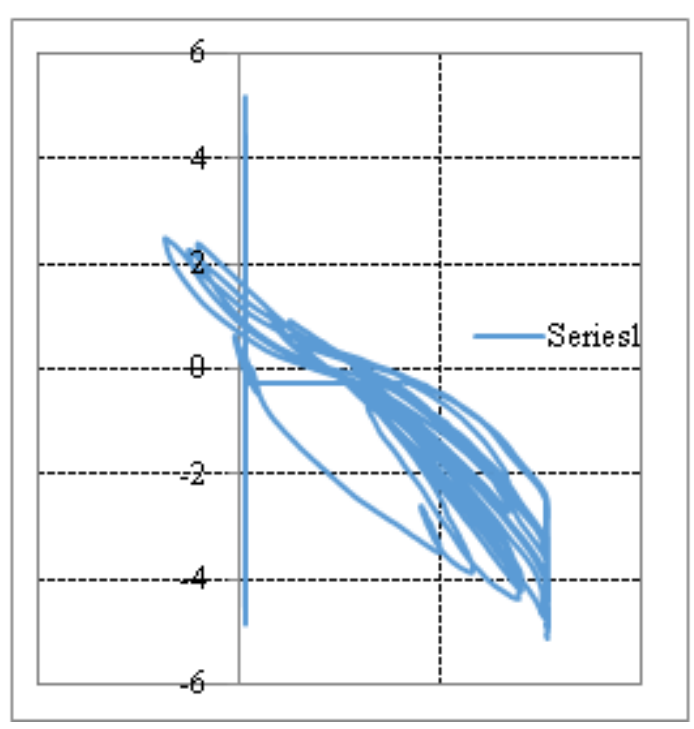

Graph 1

\section{Test for Pre-Loading}

For pre-loading (i.e,) applying upto $75 \%$ of the maximum load,the setup is same as shown in figure 5.For calculating this method three specimens are taken in which the hybrid laminates are attached at three different combinations. In this method the frequency applied to the specimen is calculated by taking $75 \%$ of the load-displacement taken for the previous control specimen. The same method of testing is done for all the three specimens taken for testing. The first crack was appeared at $\pm 2 \mathrm{~mm}$ much closed to the BeamColumn joint control specimen.

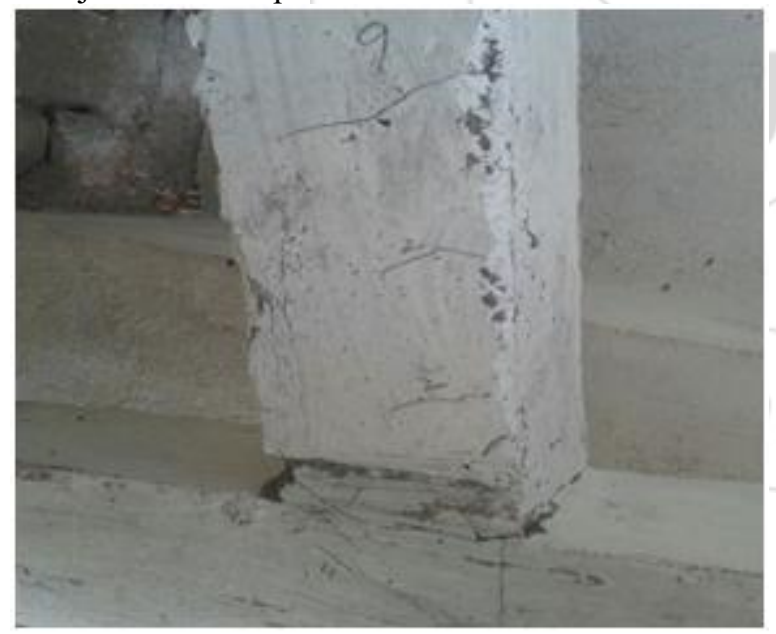

Figure 5

\section{Addition of Laminates}

Hybrid laminates are fixed to the beam-column joints after pre loading is done. Different types of attachments are shown in the below Figure.6.

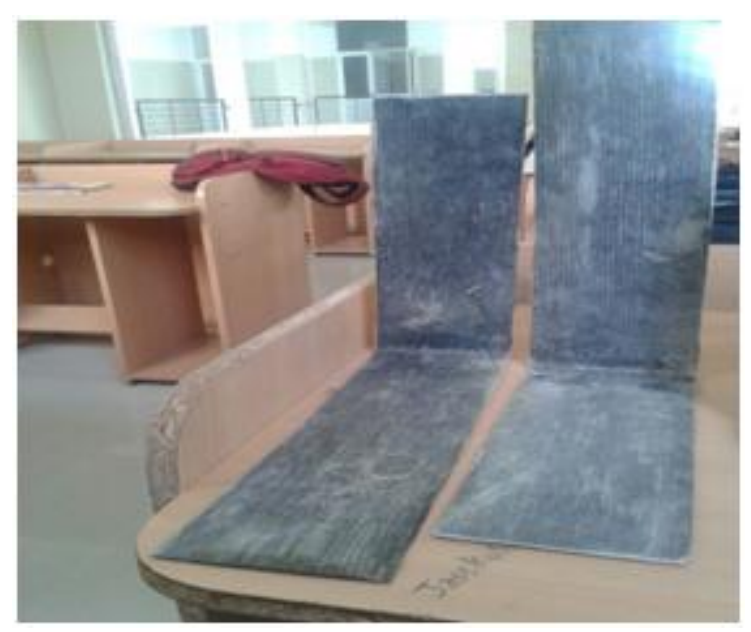

Figure 6

Carbon Fiber is made of carbon crystals aligned in a long axis. These are honeycomb shaped crystals organize themselves in long flattened ribbons. This crystal alignment makes the ribbon strong in the long axis. Fiberglass (or fibreglass) is a type of fiber reinforced plastic where the reinforcement fiber is specifically glass fiber. The glass fiber maybe randomly arranged, flattened into a sheet (called a chopped strand mat), or woven into a fabric. Fiberglass sheet laminating is the process of taking a thin fiberglass sheet and laminating it to another material in order to provide strength and support to that material.

\section{Comparison of Test Results}

For the specimen shown in fig 5after the addition of laminates using three different techniques shows the load gets increasing gradually for all the three specimens. Therefore peak values of the load corresponding to first cycle for each of the displacement amplitude were used to plot envelope curve. It can be observed that the envelope curve for HFRP specimens shows improvement in ultimate load carrying capacity in the push and pull direction. The improvement percentages of ultimate load carrying capacity are $25 \mathrm{kN}$ a respectively at maximum. The envelope curves reflect nonlinear behaviour of the tested beam-column joints.

From the above results and graphs following observations are made:

Table 1

\begin{tabular}{|c|c|c|}
\hline Sr.No & Laminates description & $\begin{array}{c}\text { Increase in } \\
\text { strength }\end{array}$ \\
\hline 1 & Normal joint & $17 \mathrm{kN}$ \\
\hline 2 & Laminates at parallel joint connection & $28 \mathrm{kN}$ \\
\hline 3 & $\begin{array}{c}\text { Laminates at perpendicular joint } \\
\text { connections }\end{array}$ & $25 \mathrm{kN}$ \\
\hline 4 & Laminates at alternate directions & $27.5 \mathrm{kN}$ \\
\hline
\end{tabular}

\section{Conclusion}

Seismic retrofitting has now become a crucial issue. Recent occurrences of earthquakes in different parts of the world have clearly demonstrated the urgency of repairing seismic deficient structures. Design guidelines and recommendations should be made more readily available to ensure more rapid and effective applications of FRP as a seismic material. In 
spite of the significant research being reported on their structural mechanism and performance, there are still great deal of concerns regarding possible premature failure due to debonding, especially in zones of combined flexural and shear stresses. More research needs to be conducted addressing issues related to mechanics, design, and durability of FRP retrofitted concrete and steel systems to ensure a proper use of FRP composites in seismic retrofitting applications.From the research and from the result of this research project we can conclude that the hybrid laminates (glass and carbon) wrapped gives better strength as compared to ordinary beam-column joint connections. Hybrid laminates wrapped at both sides gives higher strength but as the material is costly it increasing the cost of construction so from an economic point of consideration of hybrid laminates wrapped to the beam-column joint is desirable.

\section{References}

[1] Abdelhady,HamdyShaheen,AmrAbdelrahman,TamerEla fandy(2006), 'Performance of reinforced concrete beams strengthened by hybrid FRP laminates', Cement and concrete composites Vol.28 .pp.906-913.

[2] Costas P. Antonopoulos and Thanasis C. Triantafillou(2003), 'Experimental Investigation of FRPStrengthened RC Beam-Column Joints',Journal of composites for construction Vol.7 .pp.39-49.

[3] Esmaeel Esmaeeli, Joaquim A.O. Barros, Jose SenaCruz, Luca Fasan, Fabio Raimondo Li Prizzi, José Melo, Humberto Varum(2014), 'Retrofitting of Interior RC Beam-Column Joints Using CFRP Strengthened SHCC: Cast-in-Place Solution',Composite Structures,Vol.122 .pp.456-467.

[4] Farshid Jandaghi Alaee and Bhushan Lal Karihaloo, (2003), 'Retrofitting of Reinforced Concrete Beams with CARDIFRC', Journal of composites for construction, Vol.7 .pp.174-186.

[5] IS 456: 2000, 'Plain and Reinforced concrete-code of practice', Bureau of Indian Standards, Manak Bhavan, New Delhi, India.

[6] IS 10262:2009, 'Indian standard concrete mix proportioning-guidelines', Bureau of Indian Standards,New Delhi, India.

[7] Krishna N. Raju ,'Design of reinforced concrete structures', Satish kumar jain for CBS publisher \& distributors, Shahdra, New Delhi, India.

[8] Mohamed H. Mahmoud, Hamdy M. Afefy, Nesreen M. Kassem,Tarek M. Fawzy(2014), 'Strengthening of defected beam-column joints using CFRP',Journal of Advanced Research Vol.5 .pp.67-77.

[9] SP 16:1980, 'Design aids for reinforced concrete to IS 456:2000', Bureau of indian standards, Bahadur shah zafar marg, New Delhi, India.

[10] Uma.S.R. and Sudhir K. Jainb(2009), 'Seismic design of beam-column joints in $\mathrm{RC}$ moment resisting frames review of codes',Journal for possible publication,Vol.23 .pp.579-597.

[11] Varghese P.C., 'Advanced reinforced concrete design', PHI private limited, New Delhi. 